Research Article in Section Marine Mammals

\title{
Solution to Orcas in Captivity
}

Macie Zhong ${ }^{1}$

${ }^{1}$ Hasting Middle School, Upper Arlington, Columbus, Ohio 43220, USA

*Correspondence: maciezhong@gmail.com

(Received: 02/29/2020; Accepted: 04/11/2020; Published: 04/15/2020)

DOI: https://doi.org/10.37906/isteamc.2020.1

\begin{abstract}
Orcinus orca, also known as killer whales, are one of the most endangered and captured marine species. They have been kept in captivity at marine parks and aquariums such as SeaWorld and Marineland for decades just for entertainment purposes. How can people find a way to make the living conditions of these whales better? Dr. Ingrid Visser found in her study at Marineland of Antibes, France, that orcas get many physical problems through their living conditions. Their teeth are worn down, and they mostly stay in one place. Signs of aggression are also visible, as the whales rake each other with their teeth, which can cause bleeding and sometimes infections. Aggression is not only between whales, but also towards many trainers who suffer through accidents that include the death of SeaWorld trainer Dawn Brancheu. Many solutions have been suggested to solve the problems while working in cooperation with entertainment companies, but none of them have made any progress. What can people do to finish properly what we started?
\end{abstract}

Keywords: Orcas; Killer whales; Captivity; Marine parks

\section{Introduction}

Orcinus orca, also known as killer whales, are one of the most endangered and captured marine species. Many scientists and researchers consider orcas to be a whale, due to their massive size, but they are actually a part of the dolphin family. A male killer whale generally weighs up to 9,000 kilograms, and a female orca may weigh up to 5,500 kilograms at most (National Geographic Partners, 2020). These marine mammals can range from small to large. Males can grow up to 9.8 meters, and females can grow up to 8.5 meters, making them the largest member of the dolphin family (National Geographic Partners, 2020). Killer whales have been in captivity for centuries purely for entertainment purposes. Studies have been done to orcas at SeaWorld and many other marine parks that show the damage done to killer whales internally and externally. In the last 60 years, there have been at least 49 publicly announced orca deaths at Seaworld, and at least 166 globally (Whale and Dolphin Conservation, 2019). Few killer whales live to be past 17 in captivity, while killer whales in the wild typically live to be 30, with a maximum life span of 60-70 for males and 80-over 100 for females (Peta, 2019). Premature deaths are caused by inability to swim, lack of social communications, chewing on concrete, and many more.

In the wild, orcas swim up to 200 kilometers a day (Peta, 2019). Orcas in captivity mostly stay stationary in the tank, except for the shows where they will perform for up to 30 minutes (Meah, 2017). An orca would have to take at least 4280 laps around an average sized performance pool to even start to get the exercise they need on a regular basis (Peta, 2019). Having no room to move will sometimes cause acts of aggression. 
John Hargrove states "There is no room for these whales to run," in his book Beneath the Surface which emphasizes and explains the wrongdoing done by SeaWorld and the truth beyond the 2013 film Blackfish (Hargrove, 2015). Orcas can sometimes get aggressive towards other whales and trainers (Peta, 2019). Aggression towards other orcas are usually because they are asserting dominance, which is important in a killer whale's social status (Hargrove, 2015). An orca's social structure is formed around the concept of matriarchy (B. C. Cetacean Sightings Network, 2020). A female always has dominance over males, but a female that is the strongest and has the most desire for attention is essentially the dominant one in captivity. Since these whales were all pulled from different parts of the world and from different pods, most of them don't get along (Peta, 2019). If any whale upset the dominant whale of her calves, then it is likely that they will be violently raked (Ric O'Barry's Dolphin Project, 2020). Raking is when one whale uses his or her teeth to cut into and harm another whale. Orcas can also show aggression towards humans (Peta, 2019). Many trainers have been hurt or killed by orcas because of constant boredom or upset whales. Dawn Brancheau was killed in 2010 at SeaWorld Orlando, by Tilikum, the largest male orca in SeaWorld ever owned (Hargrove, 2015). In the wild, whoever has the most leadership capabilities would be the dominant whale.

These intelligent, social, and complex creatures are kept in a swimming pool just so people can be entertained. It's inhumane to keep marine mammals with a complex social structure in pools like it's a comedy show. This problem has already come too far to be easily stopped.

\section{Finding the Statistics}

Following many tragic events that occurred in SeaWorld and Lora Parque (Hargrove, 2017), orca researchers decided to look into whether or not keeping orcas in captivity was such a good idea after all. That's when Dr. Ingrid Visser decided to start studying the four whales that were kept in a small pool at Marineland (France). Dr. Visser was going to find out the real damage done to orcas in captivity, and possible solutions to killer whales in captivity. The results she found were shocking.

While Visser was studying the whales through scientific research, Jonny Meah was trying to set up a meeting with one of Marineland's animal managers, trying to get their perspective on this growing issue. After many rejections, Marineland finally agreed to do an interview with Jonny about the care of animals. What had caused these whales to start aggression towards trainers? Does their living conditions have anything to do with that? How can killer whales make a safe transition back into the wild? Only after knowing all the facts will researchers be able to start releasing whales back into the wild.

\subsection{Study of Marineland's orcas}

Jonny Meah is curious about the ever-growing debate on the captivity of orcas. Meah wants both sides (orca researchers versus marine parks) to have a say in the matter. Leaving the debate wide open, each side will get a chance to make their point, and discuss why decisions were made.

Dr. Ingrid Visser has agreed to meet with Jonny, and talk about the issue from her perspective as a marine biologist. Visser will be visiting Marineland of Antibes from a tourist's perspective, seeing everything as a guest would. This ocean themed amusement park owns animals from birds to killer whales, and has franchises internationally. Visser will also be documenting the wellness checks and activities the whales participate in throughout the week. Visser hopes to finally prove what she had known all along: the bad water conditions, small spaces, and diets are harmful for whales in captivity (Meah, 2017). Knowing the direct information from a study will help reach out to the public with the black and white truth. 
The whales will also stay stationary most of the time when they are not performing (Meah, 2017). The whales can't get enough exercise in these pools, which can further lead to health issues. How can we set up a system where the whales can be happy and healthy while people can still learn about them?

Meanwhile, Jonny was trying to get an appointment or interview with one of Marineland's animal specialists to get the perspective of a business and amusement park on the issue. After many trials and errors, Jonny finally got an interview with Marineland's zoological director, Jon Kershaw (Meah, 2017). Kershaw will lead Jonny through a guided question and answer session behind the scenes at Marineland. This tour will tell Jonny if Marineland realizes what they are doing to animals and will look ahead into their future.

\subsection{Compromise}

In order to come up with a system in which both the whales, cooperations, and visitors are happy, there needs to be the basic knowledge of what the researchers, and companies think of the issue. Without knowing the intentions of the ideas, then there will never be an ideal solution.

\subsection{Orcas at Marineland}

Marineland of Antibes, France has four orcas including a young calf. All of the whales were studied as part of Ingrid's research.

\section{The Truth about Captivity}

The results that Dr. Ingrid Visser found were breathtaking: not only were the whales forced to live under the viewing of spectators every day, they also had harsh living conditions. The whales had worn down teeth, from chewing on the walls of the tanks they were kept in (Meah, 2017). Their teeth will need to be drilled and flushed daily in order to keep it healthy (Ric O'Barry's Dolphin Project, 2020). Teeth drilling means that the whales will go under a set of procedures that keeps them out of the deep-water pools for hours (Vissor, 2017). The whales need to be shepherded into a pool that is shallow enough for trainers and doctors to stand in. Then, a harness is placed around their neck and in their mouth that keeps their jaw open. Two people will hold the rope of the harness on either side to keep the whale from moving at all (Vissor, 2017).

The whales mostly stay stationary the whole day, except for performance times (Meah, 2017), which was even worse than Ingrid had previously thought. She had thought that the whales would at least move around the pool in a circular motion (Meah, 2017). Orcas, who were used to and designed to swim hundreds of kilometers a day, were just staying stationary for $3 / 4$ of daytime and all of the night. Occasionally, the trainers will play with the whales by giving them toys and squirting water at them (Hargrove, 2015). All the behaviors that are performed during these 'play sessions' are not natural. Never in the wild would a whale push a plastic barrel around and jump up to touch a ball. Visser also found scratch and rake marks all over the whale's bodies (Meah, 2017). Rake marks are usually from aggression with another whale. It also almost never happens in the wild because of all the open water (Whale and Dolphin Conservation, 2019). In captivity, the whales have nowhere to swim (Hargrove, 2015). All of these issues, the chewing on paint, playing with balls, and aggression with each other, arise due to one reason: boredom (Meah, 2017). The whales have nothing to do, so they find ways to entertain themselves. Whales should not have to live in these harsh conditions just to entertain people. It is wrong and inhumane to keep animals with lives locked up so corporate companies can thrive.

Ingrid suggested that there should be a cove or sea pen (shown in Figure 1) in which captive whales from all around the world will be brought to (Meah, 2017). The locations of this island is not known, but 
the waters must be a suitable temperature for the whales. The white lines represent areas that will be sectioned off so the whales can be herded into different groups. This way, there will be different sections the whales can swim through and eventually some whales will be able to adjust to the wild.

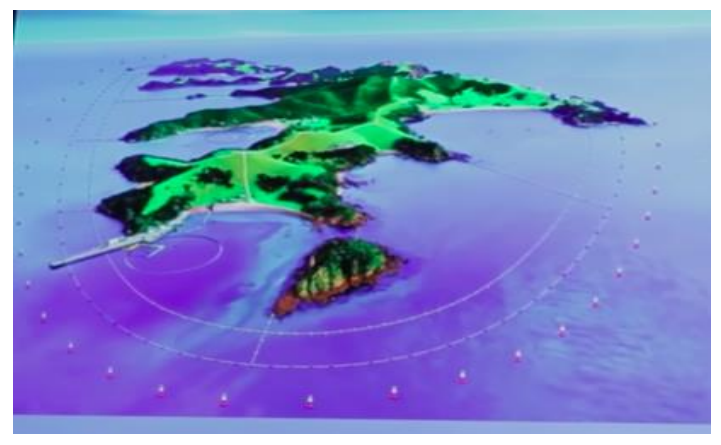

Figure 1: The general layout of the possible sea pen

As the Marineland's animal director and Jonny walked past the orca tanks, Jonny stated some of the many concerns Ingrid had mentioned earlier to him. For the tanks, Marineland admitted that they were too small and shallow for such big creatures (Meah, 2017). Kershaw also admitted that the whales were bored and therefore, they chewed and pulled paint off of the tanks for fun. This was why the tanks were so bare, and nothing was used to decorate them. It would just create more things for the whales to chew on (Meah, 2017). While this does not justify the mistreatment of the whales, it at least creates an explanation.

Marineland also brought up a new perspective: if the whales were put back out to the wild, or in a sea pen, you would still be keeping them in captivity (Meah, 2017). The whales would never be able to fully adjust to being in the wild. Kershaw also pointed out that going through all that trouble just for their four whales, would not only be unnecessary, but an awful waste of resources. If this hypothetical sea pen was built, trainers and vets would still have to take care of them. Not nearly enough fish will come through the nets and into the areas where the killer whales can catch them, so they will still need to be fed. Orcas in captivity have also taken lots of antibiotics when they were sick, and vitamins on a daily basis. How could they possibly take away all that and still have healthy whales? As Kershaw said, whales who were born in the wild live better in the wild. Whales who were born in captivity, live better in captivity (Meah, 2017).

Marineland doesn't plan on continuing to breed killer whales. The French government also banned the breeding of orcas shortly after Jonny's visit (World Animal Protection, 2019). Marineland will also keep the last of their killer whales, including their new calf, until they perish. They will be the last of Marineland's killer whale population (Meah, 2017).

Something like the sea pen that Ingrid suggested and the problems it will put up that Marineland pointed out are all aspects of a better solution. It would be best of both interests to have the whales stay in the captive environments that they are used to and have grown up in. This will ensure that the whales are healthy and not live in fear. For example, there was a killer whale named Keiko, who was captured at a young age and brought up in captivity. Keiko's home was first a Canadian aquarium and later a Mexican Zoo. His Mexican home was far from perfect. It was a low funded project so Keiko never got all the care he needed (hot, 2019). He had lots of skin problems (shown in Figure 2) and diseases that the Mexican doctors simply didn't know how to cure. Through the rough living conditions, Keiko was one of the friendliest whales that interacted with humans naturally. That was why he was chosen to star as Willy in the Hollywood film Free Willy. This hit movie made fans want to know the story of Keiko, who played their star character. 


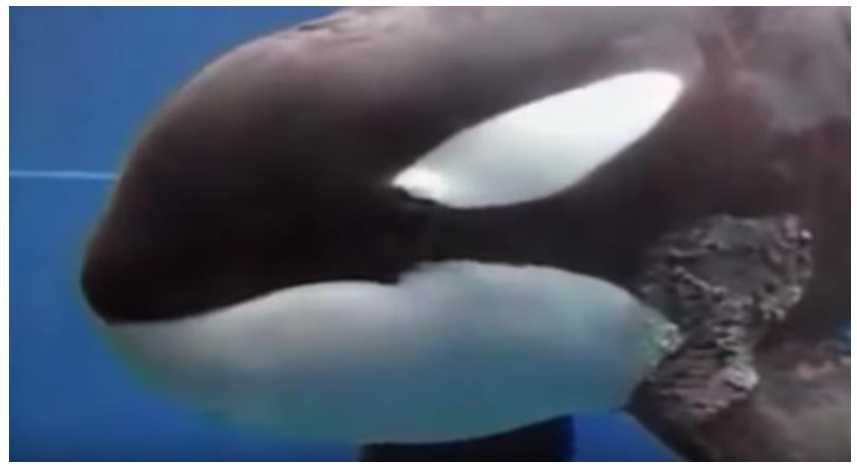

Figure 2: Keiko's skin infection (above pectoral fin)

Fans were not pleased when they found out that Keiko was still in the Mexican aquarium. They started a huge fundraiser that raised over seven million dollars. This made researchers think, and started the process of getting Keiko ready for release. After a lot of training and working, Keiko was released into Norway, where he stayed for about a year before he died of pneumonia. Even when Keiko was in the wild, he still loved people, and enjoyed having visitors and researchers go to him (hot, 2019).

Sometimes putting animals in environments that they are not used to can cause other health problems, like depression, anxiety, and constant fear. If what Marineland claims is true, then maybe it is best to keep the animals in captivity now, and try to improve their living situation (Meah, 2017). Simple actions, like not making the whales work in order to get fed, and increasing the size of the orca's pool, can make the whales a lot happier. Companies and corporations need to stop thinking about how they can make the most profit. Once people realize that they have changed, and that what they are doing is good for the whales, more people will automatically visit because they want to support the environment.

Knowing that release will not meet the orcas needs, the whales should be kept in captivity, but they should no longer perform any shows. Parks like SeaWorld should also make their environments more like the wild. Live fish will swim in the tanks and rocks will be placed at the bottom to represent a natural environment. This will allow visitors to keep seeing their beloved whales when they are actually happy. Parks and companies can still make their money and researchers can come in and study the animal itself.

With the information that Ingrid and Jonny have obtained, further research can be done to understand the details of the new renovations. Research could be done to see what changes the whales are missing in their lives, such as bigger pools, more varieties of food, and better veterinary care. If parks can provide the best living environment with a few changes, then there is no reason to start a long process of releasing whales who have been in captivity all their lives. Even though renovations may cost a lot, it is worth it for the living things living as captives all their lives.

\section{Conclusion}

A new form of education of whales should be formed. The tanks that are currently holding the whales should be turned into freeform pools. Guests that visit any of the parks should be able to see whales in their natural habitat, with live fish, algae, and rocks in the pools. The orcas will be fed daily, so that they are not performing just for food. This is the best solution with the technology we now have. Without the whales performing, they will start learning how to live a normal life again. With all the new objects put in their pool, it will feel like a mini version of a natural habitat. Guests that visit the whales will still get to see the orcas, except they will learn about them as a wild species. 
Some people may say that this process will be extremely expensive and not attractive to visitors. But most visitors would like to see animals that are happiest in the environment that they are in. The money towards renovations is about the same as the money used towards the long process of release. After the renovations are done, parks still are able to have an orca exhibit, which will still bring in profit. With all the endless performances these living things have gone through, it is the least we could do to help them live a life, from now on, where they are happy. These renovations are the best thing to do for the whales, they will finally get a chance to live as they could have.

This solution will allow parks to continue their business while the environment of their animals is improving. Visitors are happy because they are seeing and learning about whales while the companies are still making profit. Most visitors would be happier seeing whales that are happy, and not being forced to do something they don't want to do. Both sides can continue doing what they see as best fit, while the health and conditions of the whales are taken into consideration.

\section{References:}

National Geographic Partners. (2020). Killer Whale Facts. From National Geographic Kids Website: https://www.natgeokids.com/uk.discover/animals/sea-life/killer-whale-facts/

B. C. Cetacean Sightings Network. (2020). Killer Whale. From: https://wildwhales.org/speciesd/whales/killer-whale/

World Animal Protection. (2019). Canada Bans the Captivity of Whales, Dolphins and Porpoises for Entertainment. From World Animal Protection website: https://www.worldanimalprotection.us/news/canada-bans-captivity-whales-dolphins-andporpoises-entertainment?gclid=Cj0KCQjwrMHsBRCIARIsAFgSeI0tRY2tkpGoMnNcsaigrmI63ejfIp-A2IQwJ5NZZfmX3vWnYAIpsIaAmqKEALw_wcB\&gclsrc=aw.ds

Peta. (2019). 8 Reasons Orcas Don't Belong at Seaworld. From: https://www.seaworldofhurt.com/features/8-reasons-orcas-dont-belong-seaworld/

Whale and Dolphin Conservation (2019). The Fate of Orcas in Captivity. From Whale and Dolphin Conservation website: https://us.whales.org/orca-captivity/

Hogenboom, M. (2016). Why Killer Whales Should Not be Kept in Captivity. From BBC website: http://www.bbc.com/earth/story/20160310-why-killer-whales-should-not-be-kept-in-captivity

hot. (2019). That's what happened to the Willy orca after the movie [Video file]. From: https://www.youtube.com/watch?v=rdDETTlJGgk\&t=206s

Meah, J. (2017). Inside The Tanks (Full Documentary) [Video file]. From: https://www.youtube.com/watch?v=Hy9gt-f3I6Q\&t=1297s

Ric O'Barry's Dolphin Project. (2020). Orcas in Captivity. From: https://www.dolphinproject.com/resources/about-dolphins/about-orcas/orcas-in-captivity/

Visser, I. N. (2017). Killer' Toothaches Likely Cause Misery For Captive Orca. From: https://www.eurekalert.org/pub_releases/2017-10/uoo-tl101117.php

Hargrove, J. (2015). Beneath the Surface: Killer Whales, SeaWorld, and the Truth Beyond Blackfish. New York, NY: Palgrave Macmillan 